\title{
Myocardial T1 mapping in different cardiomyopathies at 3.0T
}

\author{
Juliano L Fernandes ${ }^{1,2^{*}}$, Andreas Greiser ${ }^{3}$, Strecker Ralph ${ }^{4}$, Jose Alvaro Silva ${ }^{2}$, Gabriel S Figueiredo ${ }^{2}$, \\ Jose Michel Kalaf ${ }^{2}$, Otavio R Coelho-Filho ${ }^{1}$ \\ From 15th Annual SCMR Scientific Sessions \\ Orlando, FL, USA. 2-5 February 2012
}

\section{Summary}

Measure T1 times in patients with idiopathic dilated cardiomyopathy (DCM), hypertrophic cardiomyopathy (HCM), ischemic cardiomyopathy (ICM) and compare these values to normal controls using 3.0T CMR.

\section{Background}

Diffuse myocardial fibrosis has been described in different cardiomyopathies and has recently been correlated to $\mathrm{T} 1$ times measured by cardiac magnetic resonance (CMR). Despite these advances it is yet unknown whether there are differences in T1 maps among these cardiomyopathies and if CMR can distinguish different levels of fibrosis in each category. Moreover, most work on T1 mapping has been carried on 1.5T scanners with limited data on these values at 3.0T.

\section{Methods}

T1 maps were measured pre and 10 minutes after the infusion of $0.2 \mathrm{mmol} / \mathrm{kg}$ of gadolinium on 80 subjects (20 normal controls, 20 patients with ICM, 20 patients with DCM and 20 patients with HCM). Images were obtained in a mid-ventricular short axis plane using a Modified Look Locker Inversion Recovery (MOLLI) sequence. All images with different inversion times were transferred to an off-line workstation and analyzed by drawing a region of interest around the entire myocardium and fitting the data after heart rate correction. Infarct areas in patients with ICM were excluded. Values obtained pre and post contrast were compared using General Linear Model with post-hoc LSD.

'University of Campinas, Campinas, Brazil

Full list of author information is available at the end of the article

\section{Results}

The mean age of all subjects was $51.2 \pm 14.9$ years with $66 \%$ men. After contrast, a significant difference was observed among the categories regarding $\mathrm{T} 1$ times (controls $544 \pm 88 \mathrm{~ms}$, ICM $511 \pm 124 \mathrm{~ms}$, HCM $448 \pm 112 \mathrm{~ms}$ and DCM $390 \pm 111 \mathrm{~ms}, \mathrm{P}=0.004$ ) - Figure 1. Patients with DCM had significantly lower T1 values compared to both controls and ICM ( $\mathrm{P}=0.001$ and $\mathrm{P}=0.02$ respectively). HCM patients also differed significantly from controls $(\mathrm{P}=0.01)$ while patients with ICM did not differ from normal individuals $(\mathrm{P}=0.43)$. No significant differences were found among each category of cardiomyopathy or controls in $\mathrm{T} 1$ values pre contrast (controls 1243 $\pm 71 \mathrm{~ms}$, ICM $1281 \pm 99 \mathrm{~ms}, \mathrm{HCM} 1209 \pm 88 \mathrm{~ms}$ and DCM $1241 \pm 58 \mathrm{~ms}, \mathrm{P}=0.19$ ).

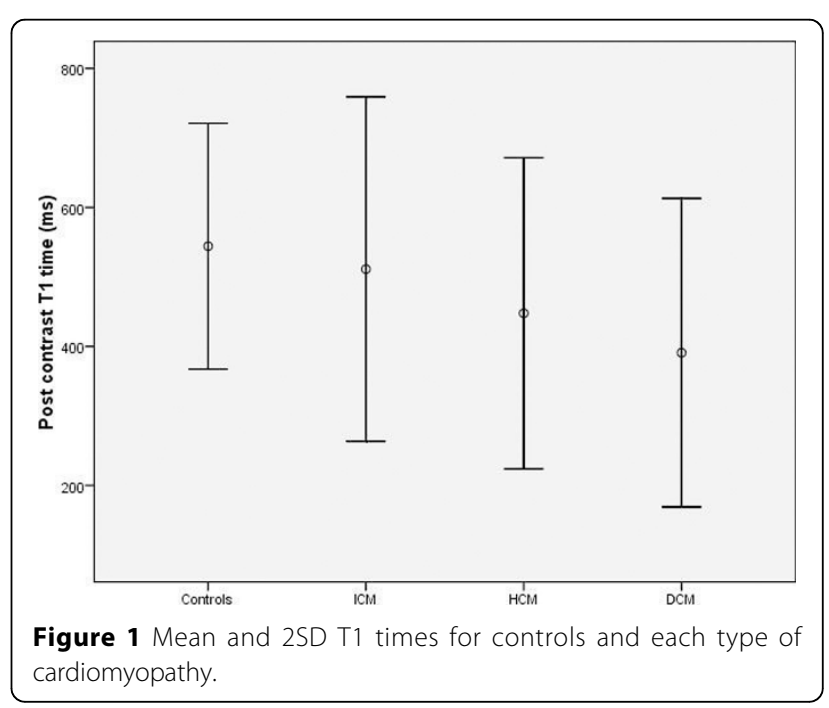

(c) 2012 Fernandes et al; licensee BioMed Central Ltd. This is an open access article distributed under the terms of the Creative 


\section{Conclusions}

Our results show that post contrast $\mathrm{T} 1$ mapping can distinguish different type of cardiomyopathies from controls at 3.0T. DCM and HCM show greatest reductions in T1 times suggesting increased diffuse fibrosis as compared to ICM.

\section{Funding}

Fundacao de Amparo a Pesquisa do Estado de Sao Paulo (FAPESP).

\section{Author details}

${ }^{1}$ University of Campinas, Campinas, Brazil. ${ }^{2}$ Radiologia Clinica de Campinas, Campinas, Brazil. ${ }^{3} \mathrm{MR}$ Cardiology, Siemens Healthcare, Erlangen, Germany.

${ }^{4}$ Healthcare MR, Siemens Ltda, Sao Paulo, Brazil.

Published: 1 February 2012

\section{doi:10.1186/1532-429X-14-S1-M13}

Cite this article as: Fernandes et al:: Myocardial T1 mapping in different cardiomyopathies at 3.0T. Journal of Cardiovascular Magnetic Resonance 2012 14(Suppl 1):M13.

Submit your next manuscript to BioMed Central and take full advantage of:

- Convenient online submission

- Thorough peer review

- No space constraints or color figure charges

- Immediate publication on acceptance

- Inclusion in PubMed, CAS, Scopus and Google Scholar

- Research which is freely available for redistribution

Submit your manuscript at www.biomedcentral.com/submit 